\title{
Translation of Chinese Traditional Cultural Elements from the Perspective of Ecological Translatology
}

\author{
Jingsi Nie \\ School of Foreign Studies, Xi'an University \\ 37316371@qq.com
}

Keyword: Chinese Traditional Cultural Elements; Ecological Translatology; Translation

\begin{abstract}
In the translation between Chinese and English, it is a relatively difficult part to translate Chinese traditional elements, so it must have a comprehensive and perfect translation system. In recent years, the translation of traditional Chinese cultural elements from the perspective of ecological translatology has gradually emerged. This paper analyzes the translation of Chinese traditional cultural elements from three aspects, such as language, communication and culture. At the same time, this paper puts forward some case studies on the Chinese translation of Chinese traditional cultural elements and has played an important role in the translation of traditional Chinese culture.
\end{abstract}

\section{Concept of Ecological Translatology}

The concept of "ecological translatology" is proposed by Professor Gengshen Hu first. With the development of ecology and the gradual emphasis on environmental protection, ecological translatology has raised the widespread concern of social groups. In addition, ecological translatology shows the relevant theory of ecological holism. For the ecological translatology, we can translate from language, culture and communication according to the essence, standard and related method of translation, which can explain the relevant contents of ecological translatology detailedly[1].

This paper analyzes the three aspects of ecological translatology carefully. First of all, the main content of linguistic aspect aspect is to use the relevant precise statement to translate the relevant content of ecological translatology through the change of language form. At the same time, clear up and analyze the translation comprehensive. The purpose of culture aspect is to convey the relevant culture of China and Britain through translation and make people have relevant cultural experience. The main content of communication aspect is to let foreign and domestic readers communicate effectively and have the same reading experience ultimately through the relevant translation. Ecological translatology eventually uses the three aspects to regulate the entire translation process. Therefore, related translators can have a better translation based on the above three aspects.

A effective interpretation of the main elements of traditional Chinese culture can provide many translation ways for translator from the perspective of ecological translatology. Translators can broaden the perspective of translation effectively through choosing translation ways of ecological translatology, which fundamentally plays the translator's dominant position.

\section{The Problems in the Translation of Traditional Chinese Culture}

China has kinds of culture with five thousand years of cultural history and fifty-six nationalities. Each nation has their own values, ways of thinking and customs. The most important content of traditional Chinese culture is people-oriented. Chinese splendid culture nurtures the people of China and is an important asset of China.

In the broad sense, the ultimate goal of translation is to narrow cultural differences and to interpret culture connotation effectively. Translation is not a language translation rather than culture 
translation seen from a certain point of view. In the trend of economic globalization, global culture has also been integrated. However, when cultures integrate, their own unique characteristics still retain in their respective religious culture, social system, economic system, etc.. Eastern culture mostly advocates nature, values humanity and objects to individualism and extremism. In addition, it also advocates people should stay harmony with nature, and "benevolence" and "filial piety" is the fundamental of oriental culture. In culture, the oriental culture is relatively conservative, which is slightly different from the Western culture. Western culture has been affected by Christianity and pay attention to private and personal rights. In addition, the thought of western culture is also more open than oriental culture[2].

As the cultural connotation of China and the West has a large difference, there is a big problem when translate, especially for the difference of history. The main reasons for the translation problem are the following two aspects.

Lack Cultural Connotation. Culture default mainly refers to some translations lack of some cultural connotation, or there is no relevant content of culture in the language translation. Language is the carrier of cultural communication, so that the cultural differences lead to linguistic differences. English is evolved from Latin and Chinese belongs to the hieroglyphs. In the process of describing things, English and Chinese also have their own different ways and rich expression style. Sometimes, when describing one thing, it may be possible to express the semantics in Chinese, but English can not find the corresponding words to express it.

traditional Chinese culture is formed by the Taoist and Confucian, which has a unique historical background. In addition, the unique language form of classical Chinese, couplet, word, two-part allegorical saying, etc., it is difficult to choose the appropriate words to express in English. Sometimes, some translators translate directly according to the letter meaning, but this kind of translation can not show the connotation, so the traditional Chinese culture will gradually disappear in the Chinese-English translation. For example, a two-part allegorical saying in Chinese, "Pig Eight looks into the mirror - inside and outside is not a person", which shows the feeling of a person in an awkward position vividly. Pig Eight is a interesting role of "Journey to the West", which is one of the four most famous Chinese masterpieces. In the process of translation, Pig Eight can only translate literally, but it is difficult for other countries to understand the cultural connotations, leading to misunderstanding or misinterpretation of the meaning of two-part allegorical saying. Besides, there are so many similar examples like this. Therefore, many Chinese cultural elements are difficult to find a suitable expression in English, which has brought a greater challenge for the translation of traditional Chinese culture[3].

\section{Use more Regression Translation Strategies}

There is a big difference between Chinese and Western cultures which is caused by history. However, when translate traditional Chinese culture, it will be assimilated simply with the Anglo-American culture when faced with greater obstacles, leading to cultural transmission errors. Although this can effectively avoid the contradictions between Chinese and English culture, it will lead to huge problem of traditional Chinese culture translation if uses regression translation strategy frequently. For example, there is a translation of "Buddha" in the traditional Chinese cultural translation. The Buddha is a deity in the eyes of Chinese people, which is formed by integrating Buddhism and local Taoism. However, some translators translate Buddha into God when translate, we all know that God is the deity of Christianity. It obviously violates the basic principles of translation to translate Buddha into God, which make foreign readers misunderstand Chinese culture and is not conducive to the spread of Chinese culture and development to a certain extent. Therefore, we must translate properly and reach the exchange of Chinese and Western cultures effectively without losing the essence. 


\section{The Influence and Inspiration of Ecological Translatology on the Translation of Chinese Traditional Cultural Elements}

Ecology translatology is a new path of translation at this stage. The translation of the existing Chinese traditional cultural elements is limited to the translation of language, but the ecological translatology interprets Chinese traditional cultural contents from a new perspective and a more comprehensive view. This paper analyzes and discusses the three aspects of ecological translatology specifically.

Linguistic Aspect Linguistic aspect mainly says that translators convert the form of language when translate, which make language form more adapt to different stages and different aspects of Chinese and Western content. Chinese and English are quite different in language form. First of all, Chinese words use more dynamic phrases, while the European and American countries relatively use more static phrases. Second, most of the Chinese sentences use a lot of punctuation, while the sentence of the European and American countries are a little longer and relatively do not attach importance to the use of punctuation. Therefore, the language of the European and American countries and China are fundamentally different. Language thinking and language structure must be converted when translate. We use the following examples.

In the famous ancient poem "Jiang Xue", there is a famous sentence like "Qian Shan Niao Fei Jue, Wan Jing Ren Zong Mie.", which can be translated into "From hill to hill, no bird in flight; From path to path, no man in sight.". The number million and thousand respectively reflects much quantity rather than the specific number in sentence. In addition, the translation effectively reflects the language characteristics and do not translate the specific number. There are a lot of vague number to show more or less quantity in the ancient Chinese language thinking. In fact, it is a use of a relatively exaggerated approach. In reality, these special expressions in classical Chinese make people feel more interesting and it is also concise in sentences. In the English translation, translators can translate the meaning of the Chinese expression effectively and highlight the content. There are many such examples, such as the famous sentence "Many people work together, there must have my teacher.". However, the number three can not be translated, while it can represent the quantity is more in English. Finally, translation will be more lively and more accurate[4].

Cultural Aspect. Cultural aspect mainly says that translators grasp the connotation of language and text effectively and explain selectively the relevant content of bilingual. As culture is different from Chinese and foreign countries, translators must focus on the study of Chinese unique language and culture system when translate. For example, translators need to translate out the characteristic of Chinese culture when translate the relevant cultural elements.

The Chinese zodiac is the unique culture of China. Dragon is Chinese unique totem and the Chinese are the descendants of the dragon. In China, the dragon represents a good luck and shows Chinese' progressive spirit. However, the meaning of "dragon" is a animal in English, which is a fierce beast and it is evil in the eyes of foreigners. This kind of translation serious misinterpretation of Chinese culture to a certain extent. Therefore, translators can translate dragon into "Chinese dragon", so that it can be distinguished from the "dragon" in the eyes of foreigners, which can truly show Chinese long traditional culture.

Chinese and English language structures often switch constantly in the process of translating Chinese traditional elements, so that translators should retain the characteristics of Chinese culture as far as possible.

Communicative Aspect. Communicative aspect mainly says that translators should translate effectively the relevant communicative content of both languages in the process of translation. Besides, the translator can focus on the content of bilingual communication. In addition, it is important to focus on whether the expression intention in the original text has been effectively reflected in the translated works. If the author seriously consider the content of communication with the reader in the process of writing, translators should also try to keep these questions when translate[5]. 


\section{Conclusion}

Through comprehensive and effective discussion and summary, we truly feel that the ecological translatology has a strong ability to explain Chinese traditional cultural elements. First of all, the ecological translatology effectively guides the translation of our traditional cultural elements and analyzes it from language, culture, communication. In addition, the ecological translators retain and screen more content through analyzing the relevant content comprehensively, making the Chinese traditional culture retained. Therefore, ecological translatology can effectively guarantee the external transmission of Chinese culture, so that the Chinese culture can spread better throughout the world.

\section{References}

[1] Bingjie Hu and Zhichen Fu. Translation of Public Signs from the Perspective of Ecological Translatology - A Case Study of the Theme Slogan of China Tibet Tourism Culture International Exposition [J]. Overseas English, 2016, (21): 113-114.

[2] Lisong Wang and Mingran Hu. Translation of Chinese Traditional Cultural Elements from the Perspective of Ecological Translatology [J]. Journal of Tianjin University (Social Science Edition), 2016, (04): 358-361.

[3] Bei Xu. A Study of Translator 's Subjectivity from the Perspective of Ecological Translatology [D]. Hubei University, 2014.

[4] Xichao Yang. Exploring the Influence of Chinese Traditional Culture on Ecological Translatology [J]. Overseas English, 2013, (07): 141-142.

[5] Wenling Wang and Ying Chu. Translation of Chinese Traditional Folk Artifacts from the Perspective of Ecological Translatology [J]. Journal of Hefei University of Technology (Social Science Edition), 2011, (05): 87-90.

[6] Honghua Zhou. Contrastive Analysis on the Translation of Taoist Cultural Elements in "Journey to the West" from the Perspective of Cultural Ecology [D]. Hubei University, 2011. 